\title{
Comparative Analysis of Solid Waste Collection in Enugu Urban- Nigeria
}

\author{
Prof. J.C Agunwamba., Asogwa Evarestus.O., Ugwuanyi Samuel. E, Engr. C. C \\ Chijioke, Dr, Timothy Adibe Nnaemeka \\ 1,2-Department Of Civil Engineering, University Of Nigeria Nsukka. \\ 3,4 And 5-Department Of Civil Engineering, Institute Of Management And Technology(Imt)- Enugu
}

\begin{abstract}
Current system of waste collection methods and facilities in Enugu Urban in Nigeria have become a significant and growing problem because it is grossly inefficient and ineffective. This research work evaluated the methods of solid waste collection in Enugu Urban by ESWAMA and suggests a plan for further comprehensive management. To collect data for the study, the collection crew of the existing ten zones were used. Random sampling was used in the zone to collect appropriate number and quality of respondents for our questionnaires and interview. Analysis of the data showed that there is a problem of indiscriminate dumping of solid waste in all the zones due to irregular and inefficient collection of solid waste and lack of suitable and adequate dust bins for the solid waste collection. The available and required total number of containers for haul container system are 28 and 265 respectively while for stationary container system are 684 and 1062 respectively. The average total cost in haul container system is N4,782,507.67 while that of the stationary container system is N17,585,808.41. The average efficiency of the collection crew for both haul and stationary container systems are $75.5 \%$ and $63.9 \%$ respectively. These results show that the haul container system is associated with higher efficiency and more less cost when compared to the stationary container system and as such is preferable. In order to improve waste management in Enugu state more suitable dust bins should be provided and professionals employed to manage waste. The government should provide more funds to the Enugu State Waste Management Authority (ESWAMA) to set up basic infrastructures needed for effective solid waste collection. Adopting these measures will improve the state of the Enugu urban environment with regard to solid waste collection.
\end{abstract}

Keywords: Solid waste, ESWAMA, Indiscriminate dumping, Random sampling and Enugu.

\section{Introduction}

Nigerian cities and towns are currently facing serious environmental problem arising from poor solid waste management. The rate of solid waste generation in Nigeria has increased with rapid urbanization. Solid waste is generated at a rate beyond the capacity of the city authorities to handle in order to maintain a sustainable urban environment. This has resulted in poor solid-waste management system that portends serious environmental crisis in most Nigeria towns and cities. The residents of some part of Enugu urban dump refuse indiscriminately along the streets, roads in open spaces, market places, frontages of residential buildings and drainage system as a result of non availability of public dust bins. This result in an unsightly mountain of refuse that has become a common feature of Nigeria's urban landscape (Ogboi and Okosun, 2003).

\section{Background}

The functional element of collection includes not only the gathering of solid wastes and recyclable materials, but also the transport of these materials, after collection to the location where the collection vehicle is emptied. This location may be a material processing facility, a transfer station, or a landfill disposal site. In small cities, where final disposal sites are nearby, the hauling of waste is not a serious problem. In large cities, however where the haul distance to the point of disposal is often greater than 15 miles, the haul may have significant economic implications. Collection of solid waste in an urban area is difficult and complex because the generation of residential and commercial-industrial solid waste takes place in every home, every apartment building, and every commercial and industrial facility as well as in the streets, parks, and even vacant areas.

The growth of solid waste has outpaced the growth of our population due to increasing urbanization, industrialization resulting in change in lifestyles, food habits and living standards. The increase in nondegradable waste is alarming. The production and consumption of non-degradable material in our lifestyle have increased many folds, and finds a way out in Dumpsites.

As the patterns of waste generation become more diffuse and the total quantity of waste increases, the logistic of collection become more complex. Although these problems have always existed to some degree, they have now become more critical because of the high cost of fuel and labor. Collection accounts for 50 to 70 
percent of the total money spent on solid waste management. This fact is important because a small percentage improvement in the collection operation can affect a significant savings in the overall cost.

\section{RESEARCH OBJECTIVES}

This work aims at achieving a well-coordinated and sustainable solid waste collection system that would be used for any city in the country. Adequate attention must be paid to all the components of a sustainable solid waste collection cycle.

Therefore if there is to be efficient solid waste collection in Enugu urban, the availability of human resources, plant, equipment and other tools including capital must be readily available. There is a need to protect future for the next generation by cleaning up our environment of all types of waste, taking into consideration both physical and population development of the state. As such solid waste collection is an important segment of solid waste management that needs attention.

The specific objectives of this research work are summarized thus:

To determine the adequacy and suitability of collection bins and vehicles.

To determine the efficiency of the collection crew.

To study the qualification and number of collection crew

To determine the frequency of waste collection

To recommend measures that will improve the quality of solid waste collection in Enugu urban.

\section{RESEARCH SCOPE AND LIMITATION}

Enugu municipal is made up of three local government areas; Enugu east, Enugu south, and Enugu north. These local governments is the heart beat of Enugu state and has over two third of the industries and companies in the state.

This cause serious rural-urban migration and also influx of people from other states and nations pending on the field of specialization of individual. The migration process increases the population of the three local governments daily thereby increasing the volume of solid waste generated. Also there is increase in industrialization which increases waste generation.

\section{RESEARCH PROBLEM}

The conventional solid waste collection practices in Enugu municipal, does not give a satisfactory efficiently service. Therefore, this research work, appraises solid waste collection activities in Enugu with a view to evolving efficient and effective solid waste management system for the city.

\section{SIGNIFICANT OF RESEARCH}

Presently Enugu municipal is facing serious environmental problem arising from poor solid waste collection practice. The following has been perceived as the intractable waste problem in Enugu municipal: Attitude to work

Lack of adequate equipment, plant and tools necessary for waste collection Corruption Population growth and standard of living.

There is therefore a need to carry out a research work on how to solve the aforementioned problems. The research work is expected to study the population growth rate, standard of living and how they affect solid waste generation. To appraise solid waste collection practice by ESWAMA and suggest possible practical means of improvement.

\section{Result And Discussions \\ EFFECT OF WASTE COLLECTION MODE ON EFFICIENCY}

From the graphs below in (figs.1) it can be depicted that haul collection mode is associated with higher efficiency when compared with stationary collection mode. There are variations in efficiency with respect to the zones for the two collection modes. These variations is as a result of factors like pick -up time, the time per trip, the allowable off route activity time, and the total time consumed during the solid waste collection. In haul container system these factors are related to one container at a time, therefore efficiency appreciates while in stationary container system so many containers are involved thereby retarding efficiency. From the analysis carried out, the efficiency of the haul and stationary container system are $75.5 \%$ and $63.9 \%$ respectively.

\section{EFFECT OF WASTE COLLECTION MODE ON COST COAL CAMP}

From the graph below (fig. 4). The findings reveal that there is competition existing between the haul and stationary container system. This competition decreases as the round trip distance increases. This suggests 
that there is a direct relationship between the round trip distance and weekly cost. It can be deduced from the graph below that the stationary container system is more cost oriented than the haul container system. The total cost associated with the haul container system of this zone with respect to the average weekly operational cost, the average weekly maintenance cost and the capital cost is=N4,736,520.8 while the total cost of the stationary container system is $\mathrm{N} 19,567,800$

\section{OGUI ROAD}

From the graph below (fig. 5) it can be deduced that the competition existing between the haul and the stationary container system ceases to exist at the round trip distance of $31 \mathrm{~km}$. The graph shows the disparity in cost between the two modes at different round trip distances. A conclusion can be drawn from the graph that stationary container system is more cost oriented than haul container system. The total money spent on the haul container system comprising the average weekly operational cost, the average weekly maintenance cost, and the capital cost $=\mathrm{N} 4741032.8$ while that of the stationary container system is $\mathrm{N} 19,728,000$.

G.R.A

Conclusion can be drawn from the graph below (fig. 6) that stationary container system is more cost oriented than haul container system. It is equally noted that there is corresponding increase in the weekly cost of the two collection mode as round trip distance increases. Therefore round trip distance is one of the factors that determines cost for the two collection modes. The total amount of money spent on the haul container system, comprising of the average weekly operational cost, the average weekly maintenance cost and the capital cost $=\mathrm{N} 4,874,683.2$ while that of the stationary container system $=\mathrm{N} 18,191,560$.

\section{EMENE}

The result of the graphical analysis in the fig.11 below shows that the cost incurred in solid waste collection increases as round trip distance increases for both haul and stationary container system. The competition between theses two collection modes decreases as the round trip distance increases. The total cost associated with the haul container system, comprising the average weekly operational cost, the average week[y maintenance cost and the capital cost $=\mathrm{N} 4,743,391.5$ while that of the stationary container system $=\mathrm{N} 17,063,240$.

\section{ABAKPA ZONE}

From the graph below (fig. 8) it can be concluded that stationary container system is more cost oriented than haul container system. It can equally be deduced from the graph that the average weekly operational cost for the two collection modes increases with increase in round trip haul distance. The sum total of N18,174,560 was spent on operating the stationary container system while $\mathrm{N} 4,874,925$ was spent on operating the haul container system. The competition between the two collection modes ceases to exist at the round trip distance of $34 \mathrm{~km}$. At this point, the total amount of money spent on the two collection modes are equal.

\section{AGBANI ROAD.}

From the graph below (fig. 13) it can be depicted that the weekly operational cost increases as the round trip distance increases. The competition existing between the two collection modes decreases as round trip distance increases. The total amount of money spent on operating the haul container is N4,751,564.3 while that of the stationary container is $\mathrm{N} 17,833,859.5$

\section{INDEPENDENCE LAY-OUT.}

Conclusion can be drawn from the graph below (fig. 9) that the weekly operational cost increases as the round trip distance increases. The competition existing between the two collection modes decreases as round trip distance increases. The total amount of money spent on operating the haul container is N4,750,477.1 while that of the stationary container is N15,920,760.5

\section{TRANS- EKULU.}

The result of the graphical analysis of fig .7 below shows that the cost incurred in solid waste collection increases as round trip distance increases for both haul and stationary container system. The competition between these two collection modes decreases as the round trip distance increases. The total cost associated with the haul container system, comprising the average weekly operational cost, the average weekly maintenance cost and the capital cost $=\mathrm{N} 4,851,243$ while that of the stationary container system $=\mathrm{N} 17,931,988.1$.

The margin existing between the total amount of money spent on the two collection mode is an evidence that stationary container system is more cost oriented. 


\section{ACHARA LAY-OUT.}

From the graph below (fig. 10) it can be depicted that stationary container system consumes more money than haul container system . The cost of operating the two collection modes increases as the round trip distance increases. And the competition existing between the two collection modes decreases as the round trip distance increases. The total sum of N4,891,905 was spent on operating haul container system while $\mathrm{N} 15,762,764$ was spent on stationary container system.

\section{NEW HAVEN}

From the graph below (fig. 12) it can be deduced that the competition between the two modes are strong. And that competition decreases as round trip distance increases. It can equally be concluded that during the study period, the sum total of the money spent on the stationary container system $(\mathrm{N} 15,683,552)$ is greater than that of the haul container system $(\mathrm{N} 4,609,334)$.

\section{COMPARISON BETWEEN DIFFERENT MODES.}

A conclusion can be drawn from the graph below (fig. 2) that haul time increases as the round trip haul distance increases for both haul and stationary container system. Also from the graph below (Fig. 3): The average pick-up time computed in the haul and stationary container system are 19.5minutes and 304.626minutes respectively. Also the average collection time computed in the haul container system is 80.687 minutes while that of the stationary container system is 279.398 minutes. Therefore, the total time consumed during the collection operation which is directly dependent on the pick-up time and the collection time is greater in stationary container system than in haul container system. The average efficiency of the collection operation in haul and stationary container system are $75.5 \%$ and $63.9 \%$ respectively. Meaning that greater efficiency is recorded in haul container system than in stationary container system. The average number of available and required bins for the haul container system are 3 and 68 respectively while that of the stationary container system are 68 and 106 respectively. The average capacity of the available and required bin of the haul container system are $6.217 \mathrm{~m}^{3}$ and $18.5 \mathrm{~m}^{3}$ while that of the stationary container system are $1.09 \mathrm{~m}^{3}$ and $6 \mathrm{~m}^{3}$.

\section{COMPARISON BETWEEN BETTER MODE WITH RESPECT TO COST AND EFFICIENCY.}

From the result of the analysis carried out, it was noted that haul container system is a better mode when compared to the stationary container system . The average total cost comprising, the average weekly operational cost, the average weekly maintenance cost and the capital cost in haul container system which is $\mathrm{N} 4,782,507.67$ is far much less than that of the stationary container system which is N17,585,808.41. The different in the total cost of the two collection modes is a clear evidence that haul container system is better than stationary container system with respect to cost.

The average efficiency of the collection crew in haul container system as computed in table 1 is $75.5 \%$ while that of the stationary container system in the same table is $63.9 \%$. The result shows that haul container system is associated with higher efficiency and as such is recommended as a better mode.

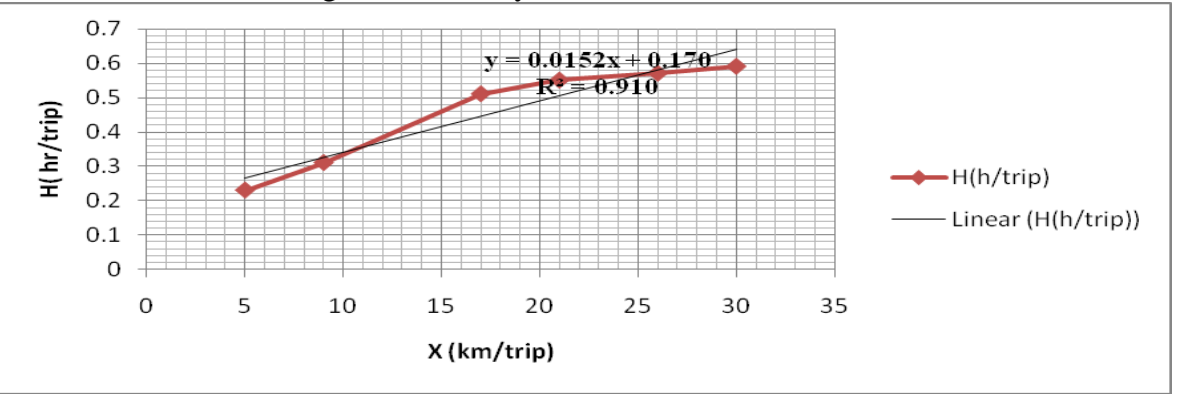

Figure 1: Relationship between haul time versus haul distance

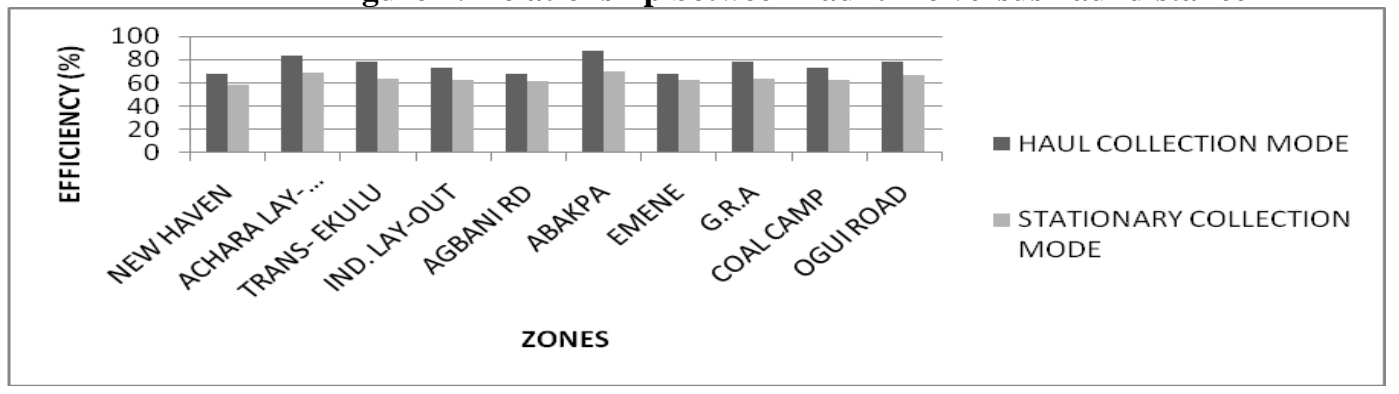

Figure 2 Comparison between haul and stationary container system with respect to efficiency. 


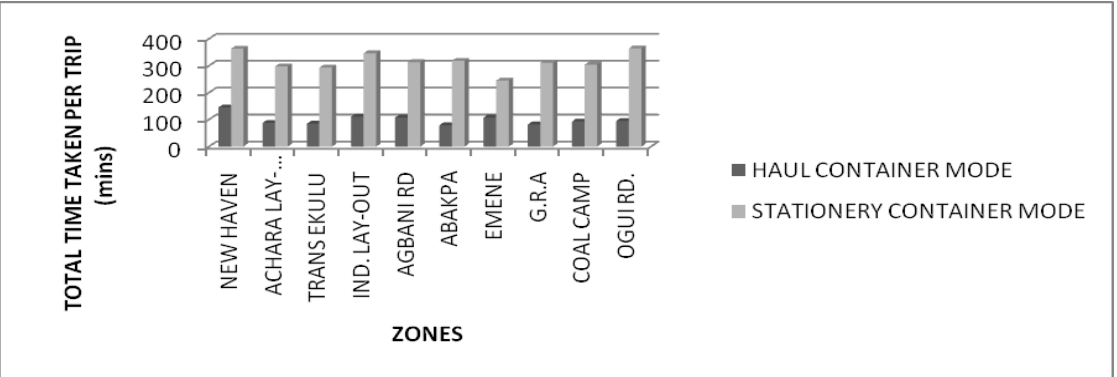

Fig. 3 Comparison between haul and stationary container system

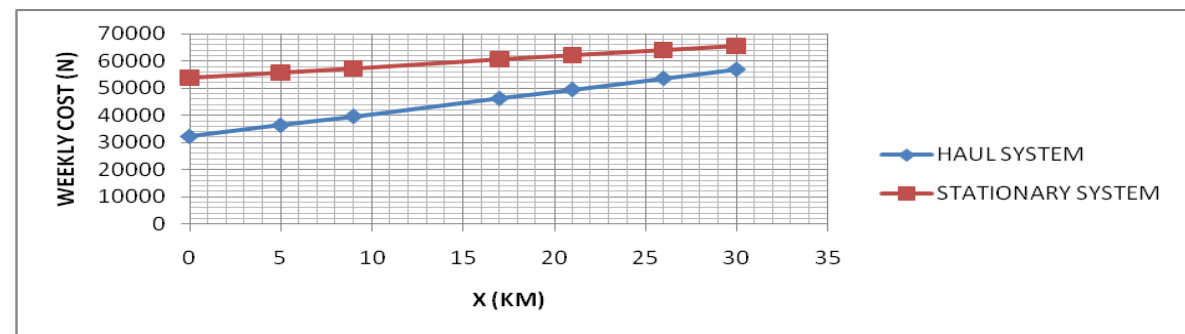

Fig. 4 Comparison between haul and stationary container system with respect to cost at coal camp zone Enugu.

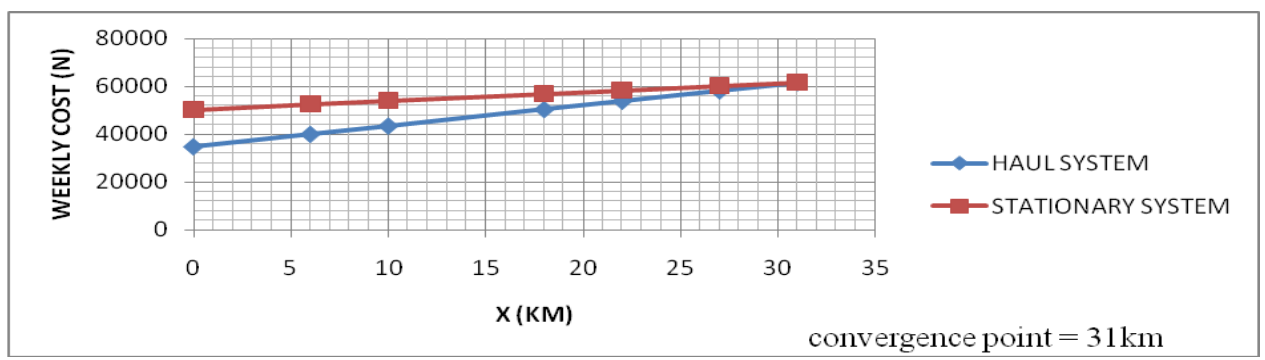

Figure 5 Comparison between haul and stationary container system with respect to cost at Ogui new layout Enugu.

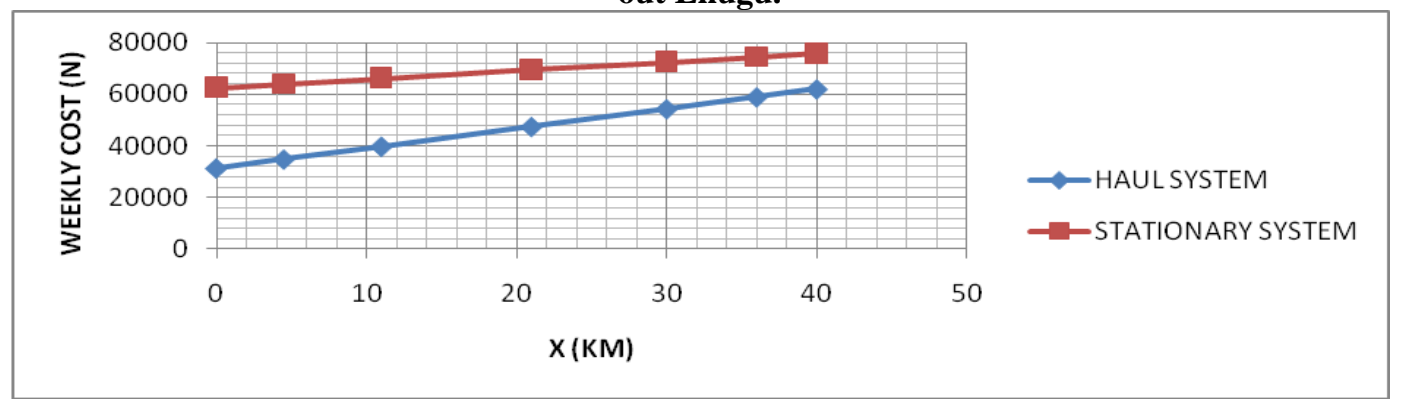

Fig. 6 Comparison between haul and stationary container system with respect to cost at G.R.A Enugu.

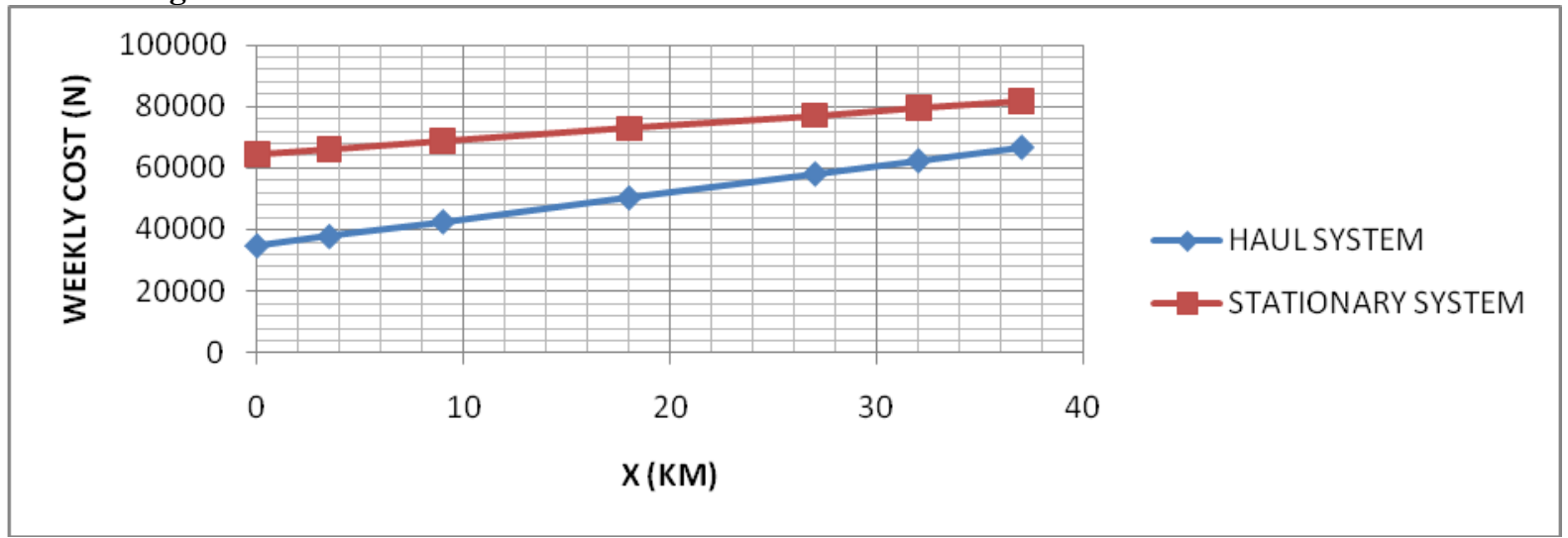

Figure 7 Comparison between haul and stationary container system with respect to cost at Trans -Ekulu. 


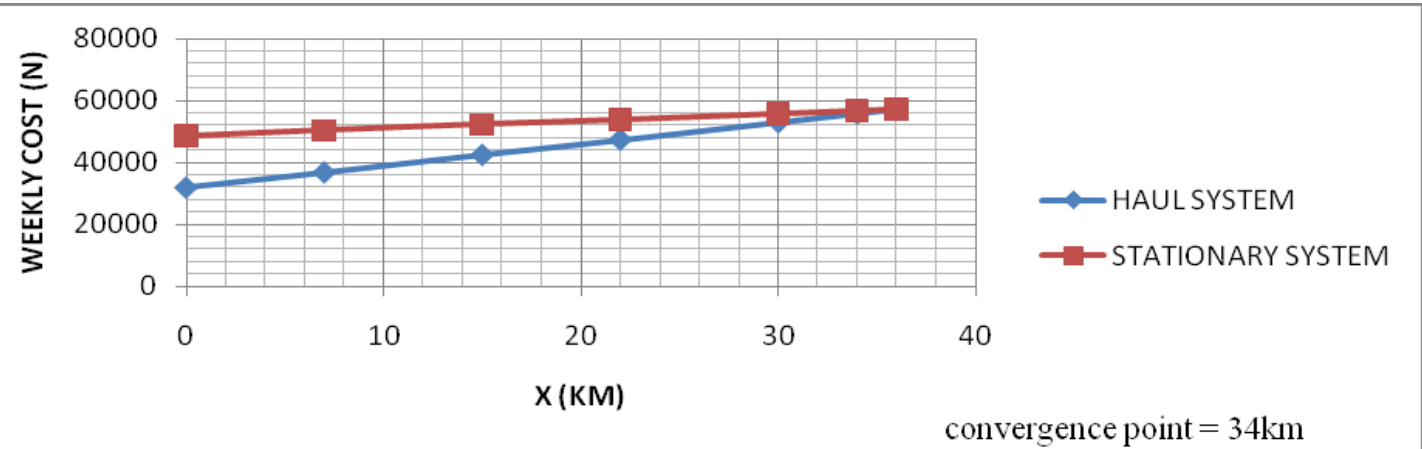

Figure 8 Comparison between haul and stationary container system with respect to cost at Abakpa.

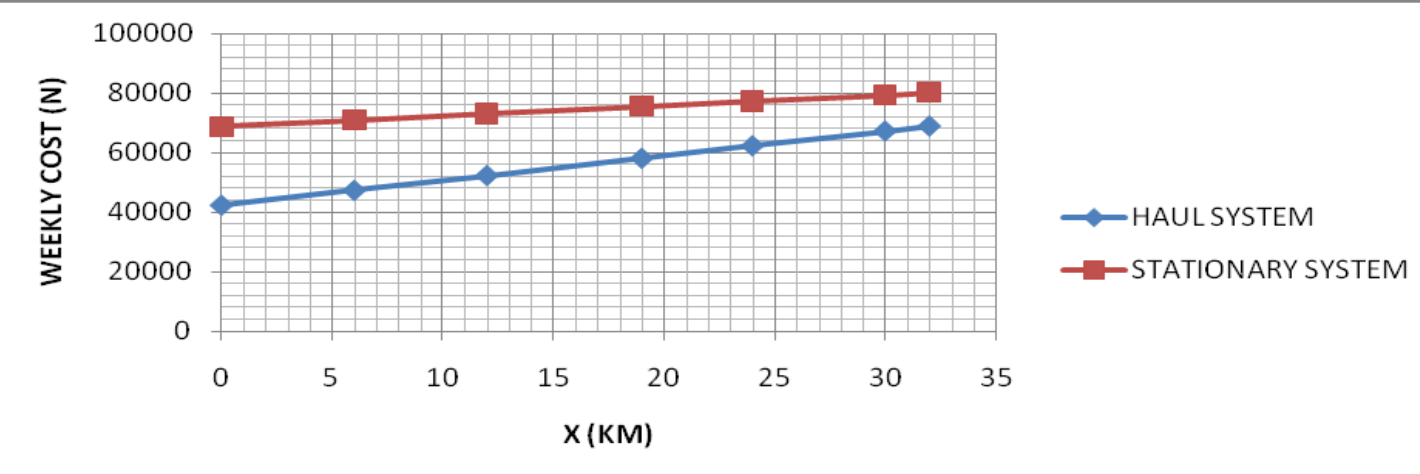

Figure 9 Comparison between haul and stationary container system with respect to cost at Indepedence lay-out

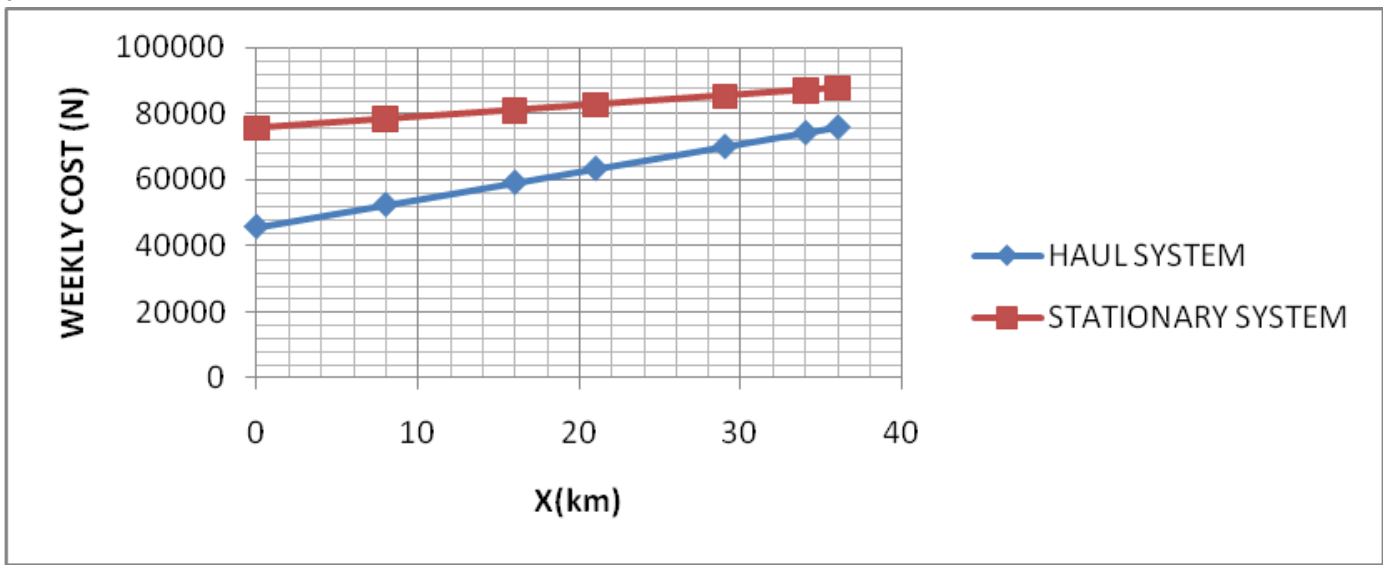

Figure 10 Comparison between haul and stationary container system with respect to cost at ACHARA lay-out.

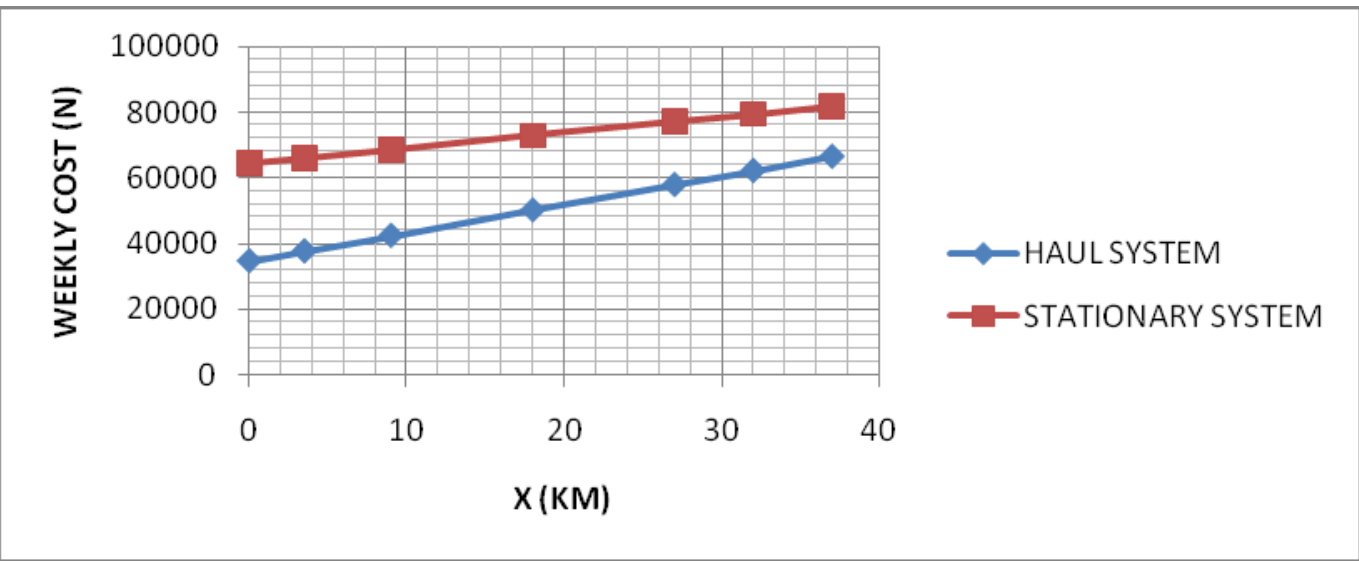

Figure 11 Comparison between haul and stationary container system with respect to cost at Emene. 


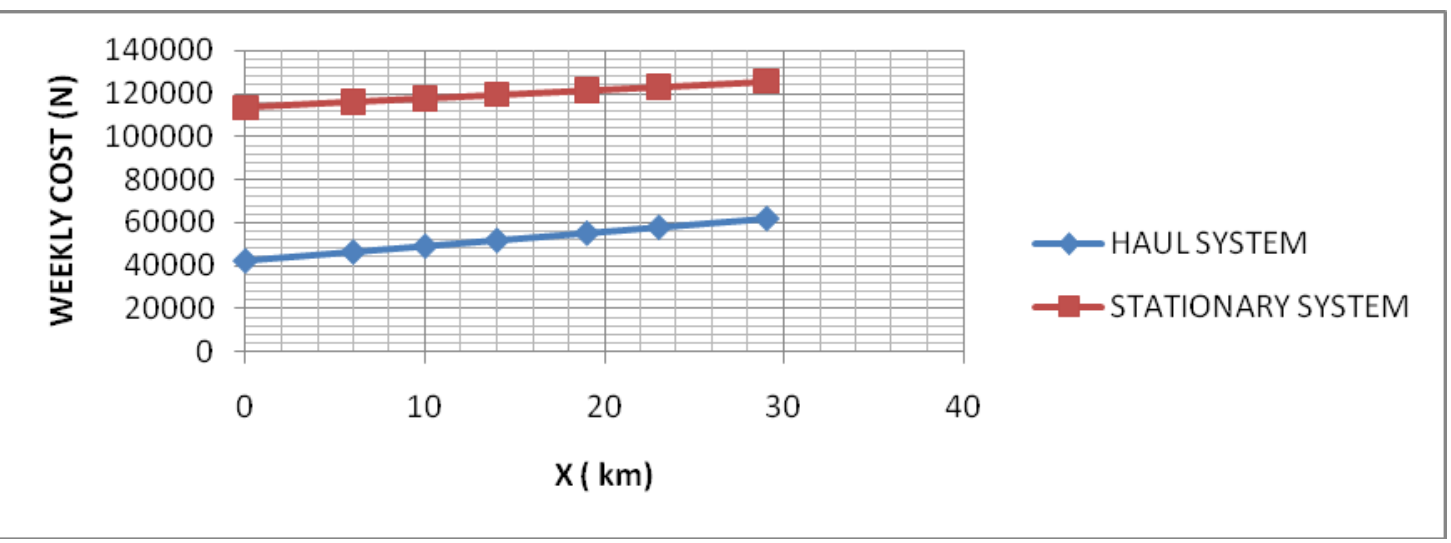

Figure 12 comparison between haul and stationary container system with respect to cost at New heaven.

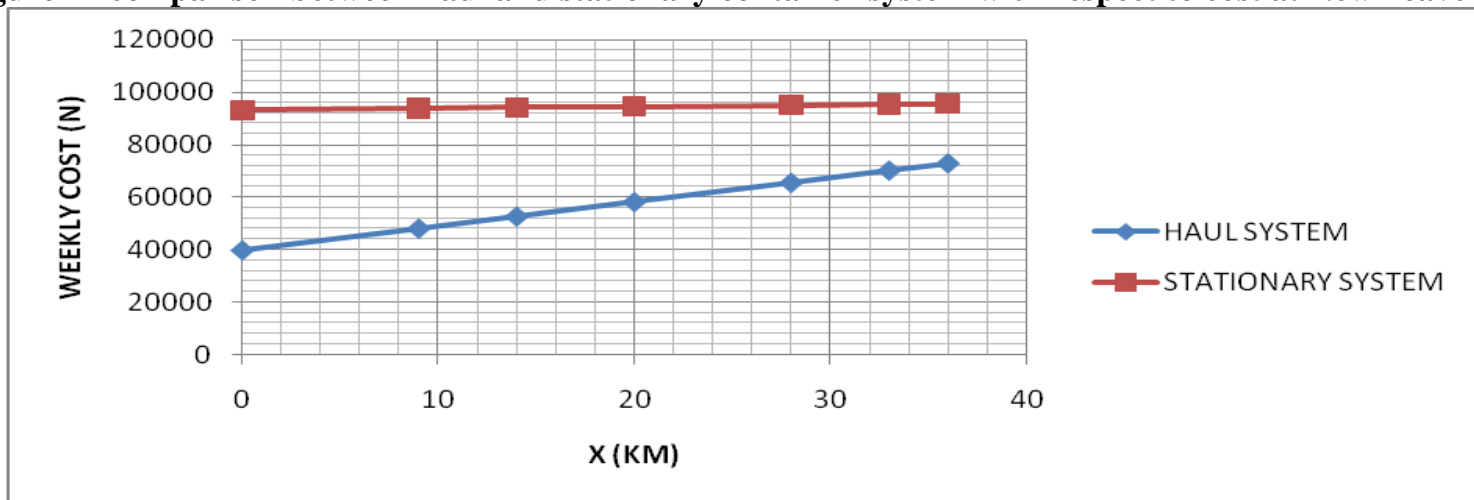

Figure 13 Comparison between haul and stationary container system with respect to cost at Agbani.

Table 1: WASTE COMPOSITION AND SOURCES

\begin{tabular}{|l|l|}
\hline KIND & COMPOSITION \\
\hline Garbages & The waste from preparation, serving of foods; market wastes, storage and sell of product \\
\hline Rubbish & Combustible, non combustible, paper, carton, boxes, wood furniture \\
\hline Ashes & Residential from fire used for cooking and heating \\
\hline Industrial waste & Food processing waste, scraps \\
\hline Demolition & Plumbing parts, bricks, blocks \\
\hline Construction & Scraps \\
\hline Special wastes & Hazardous solids and liquids, materials, hospital wastes. \\
\hline Sewage treatment residue & Solid from coarse screens \\
\hline Animal and agric waste & Manures, crop residues \\
\hline
\end{tabular}

Source : Adapted from American public works Association (APWA) Refuse collection practice, Washington, 1966.

\section{CONCLUSION}

\section{Conclusion And Recommendation}

In this research, we made a detailed study on the collection of solid waste in Enugu urban and the way in which the waste collected is been disposed by ESWAMA. Generally, adequate attention is presently not paid to solid waste collection in most Nigerian towns including Enugu urban. The results are deteriorated public health, which can lead to outbreak of epidemics and environmental degradation. Dividing the study area into ten zones enabled us to make an in-depth study of the research area and varying results were obtained. Natural peculiarities influenced greatly the differences in the results obtained from the zones.

It was found from the result of the analysis carried out that solid waste collection in Enugu urban differ from zone to zone with respect to cost and efficiency. Despite the fact that there are in some zones a few number of public collection dust bins for dumping solid waste for appropriate collection by the waste collection agency, we found out that at the approved solid waste collection centers, the collection agency (ESWAMA) is not regular in the collection of the waste resulting to overflowing sites. This inadequacy in the collection of solid waste was discovered to be due mainly to poor funding of the agency by government, Non availability of sanitary Engineers in the work force, non payment of sanitation rates by residents, and attitude to work by the waste collection workers.

The graphs (fig. 1- fig. 2) are characteristics of those obtained when hauled container systems were compared with stationary container systems. From the graph, as round trip haul distance increases, the weekly 
operational cost increases in both haul and stationary container system. It can be depicted that more money is being spent weekly in stationary container system than in haul container system. The average efficiency of the collection crew in haul container system as computed in table 1 is $75.5 \%$ while that of the stationary container system in the same table is $63.9 \%$. The result shows that haul container system is associated with higher efficiency, and as such is recommended.

From the analysis carried out, where it was assumed that the waste is being sorted at the source of generation before disposal, the following were observed:

a) That time spent per trip reduced

b) That the number of trips made in a week reduced

c) That there is reduction in the container size

d) That the efficiency improves.

e) That there is reduction in the quantity of container.

From the analysis carried out, it was observed that there is variation in the efficiency of the collection crew of the ten zones and the associated dust-bins inadequate in number and size. It was equally found that the dust-bin of the stationary container system is not suitable as it is damaged easily because of the liter nature of the material used for the construction. From the analysis carried out, the qualification of the collection crew is not encouraging hence most of them are not technically sound. Also trucks used for the waste collection are not adequate in number.

From the analysis of the operational cost of both haul and stationary container system, it is noted that stationary container system is more cost effective when compared to haul container system. It is equally noted that operational cost is dependent on round trip distance.

\section{RECOMMENDATIONS}

Based on the findings of this research, we make the following recommendations which are expected to improve the system of waste collection in Enugu Urban.

* Government funding on waste management should be mainstreamed into the budget plan for each year and the funds for this purpose disbursed on time for procurement of trucks and other materials necessary for waste management and payment of workers engaged in the task.

* That the platform of each dust bin stand point should be constructed in a way that it does not obstruct both traffic and pedestrians.

* That Government should enforce a law that every waste generated must be sorted at the point of generation before disposal.

* That the haul container system will be made dominant, in the collection system as it less lost effective.

* Private agencies (Non-Governmental Organizations) should be encouraged to participate in funding, provision/donation in materials personnel and taking up responsibilities of paying for staff who work to keep the city clean. Furthermore, government needs to engage and work with the private sector in this enormous challenges of solid waste management.

* The required size and number of hauled and stationary container system as obtained from the analysis carried out on the ten zones that made up Enugu municipal should be made available by ESWAMA.

* That professionals should be incorporated to each collection crew in order to facilitate the efficiency of the collection crew.

* That dust bins of high quality that will be suitable for waste collection be made available by ESWAMA.

* That Government should commit more funds to the Enugu state waste management Authority (ESWAMA) to set up basic infrastructure needed for effective solid waste collection.

* Government should invest in technology and recruit experts in Geology, Engineering and Environmental Management for sustainable solid waste management in Enugu Metropolis.

* From the analysis carried out in table 2.2 , it is recommended that ESWAMA should improve the frequency of evacuation of waste.

* That public should be educated on the need to sort solid waste at the source of generation before disposal.

* That government should enforce law restricting the disposal of unsorted solid waste.

\section{References}

[1]. Adesanya, Y.O. (1986): “Constraints to Solid Waste Management: A case study of Ibadan." An Unpublished MURP Degree Dissertation.University of Ibadan.

[2]. Agbogu, L.N. (1991) "Environmental Effect of Industrial Waste:" An Unpublished BURP Degree Dissertation. Department of Urban and Religional Planning, University of Nigeria, Enugu Campus.

[3]. Buckets and Smith (1994): Introduction to Solid Waste Management. www.plastic.ca/epic.

[4]. Chukwu, A.O. (2002): "The Effect of Indiscriminate Disposal of Plastic Waste in theEnvironment: A case study of Enugu". An Unpublished BURP Dissertation of Department of Urban and Regional Planning, University of Nigeria, Enugu Campus. 
[5]. Eze, H.O and Asadu, E.C (2003): "Sustainable Solid Waste management in Enugu. A paper presented at the $34^{\text {th }}$ Annual Conference of the Nigeria Institute of Town Planners. Abeokuta, $22^{\text {nd }}-24^{\text {th }}$ October.

[6]. Ogboi K.C and Okosun, A.E. (2003): "The Role of Scavengers in Urban Solid WasteManagement In Nigeria." Environmental Studies and Research Journal Vol's No. 2, Pp 85-92.

[7]. Ogbalu, A.I (2004): "Refuse Management: The Role of Health Education.” Environmental Studies and Research Journal vol. 4 No. 2, Pp 41-53

[8]. General Auschutz, Justine 1996. Community-Based Solid Waste Management and Waste SupplyProjects: Problems and Solutions Compared. Literature Survey.Urban Waste Expertise Programme, Community Participation in Waste Management, UWEP Working Document $\quad 2^{\text {nd }}$ May.http://www.waste.n1/redir/content/download/606/4651/file/WD02.pdf

[9]. Bartone, Carle R. (1997). Strategies for Improving Urban Waste Management: Lessons from a Decade of World Bank Lending. HazWaste World/Superfund XVII Conference, Washington,D.C. http://www.undp.org/pppue/pppueold/library/files/barton01.doc.

[10]. Bernstein, J. (2004). Toolkit for Social Assessment and Public Participation In MunicipalSolid Waste Management. Urban Environment Thematic Group, The World Bank, Washington, D.C. http://www.worldbank.org/urban/uswm/socialassesstoolkit.pdf

[11]. Beede, David N., and D. E. Bloom (1995).The Economics of Municipal Solid Waste. The World Bank Research Observer 10(2): 11350. Available for purchase from http://www.worldbank.org/research/journals/wbro/obsaug95/solidwaste.htm CPIS.Enterprises for the recycling and composting of municipal Solid waste, conceptual work, vol. 1. Jakarta, Indonesia: Centre for Policy and Implementation Studies (CPIS) and Harvard Institute for International Development (HIID); 1993

[12]. Coad, A. (1998).Solid Waste Management Directory of English-Language Publications and Organisations for Low- and MiddleIncome Countries.SKAT. Switzerland. Available for purchase from http://www.skat.ch/publications/prarticle.2005-0929.7288084326/skatpublication.2005-11-10.3524725150

[13]. Cointreau-Levine, S., and A. Coad (2000).Private Sector Participation in Municipal Solid Waste Management: Guidance Pack (5 volumes)

SKAT

St.

Gallen, Switzerland.http://www.worldbank.org/urban/solid wm/erm/CWG\%20folder/Guidance\%20Pack\%20TOC.pdf 